\title{
Visual Accommodation System in the Eyes of a Berycid Deep-Sea Fish Beryx splendens
}

\author{
Koji Kikuchi,*1 Masaomi Asai,*2 Yasuko Kuboshima, ${ }^{* 1}$ Isamu Mitani, ${ }^{* 1}$ Tatsuya Takizawa, ${ }^{* 2}$ \\ Muneo Okiyama, ${ }^{* 3}$ and Hiroaki Somiya*2 \\ ${ }^{* 1}$ Kanagawa Prefectural Fisheries Experimental Station, Jogashima, Miura, Kanagawa 238-02, Japan \\ ${ }^{* 2}$ Azabu University School of Veterinary Medicine, Department of Developmental Biotechnology and Neuroscience, \\ Sagamihara, Kanagawa 229, Japan \\ ${ }^{* 3}$ Ocean Research Institute, University of Tokyo, Minamidai, Nakano, Tokyo 164, Japan
}

(Received May 23, 1994)

\begin{abstract}
Efferent arrangements of the accommodation system are examined in the eyes of a berycid deep-sea fish, Beryx splendens. A large rectangular lens muscle and its associated ligaments and nerves are described for the first time. The relative size of the lens muscle to the lens muscle to the lens is almost three times that of the mackerel. B. splendens may have almost the same wide accommodative range as the shallow-water sea bass. The lens muscle nerve contains about 300 large myelinated fibres. Mean fiber diameter is about $10 \mu \mathrm{m}$. The present study shows that the visual axis of $B$. splendens is directed up and forward. The ecological significance of the well-developed accommodation system in this berycid fish is discussed in connection with its feeding behavior in a deep-sea environment.
\end{abstract}

Key words: visual accommodation, eyes, deep-sea fish, Beryx splendens, lens muscle, short ciliary nerve

Beryx spp. (Beryciformes, Berycidae) are mid water deep-sea fishes which inhabit depths of 100 to $700 \mathrm{~m}$; the family is distributed worldwide. ${ }^{1)}$ Visual accommodation is an important function of the fish eye in various behaviors. Many shallow-water teleosts can accommodate their eyes by moving the lens and for this dynamic accommodation $^{2-5)}$ have a well-developed lens muscle.

Efferent arrangements of the accommodation system, i.e., the intraocular lens muscle and its associated nerves, have already been described in mackerel and bass. ${ }^{6,7)}$ However, there is little literature on the efferent accommodation system in the eyes of deep-sea fish. Only RochonDuvigneaud $^{8)}$ delineated the lens muscle of Beryx decadactylus in his classic textbook. This paper therefore describes the efferent arrangements of the accommodation system of the berycid deep-sea fish, B. splendens, and discusses the functional significance of the system in the biology of this deep-sea fish.

\section{Materials and Methods}

B. splendens was collected off Miyake Island (Tokyo) by line and hook Twenty specimens, $34-37 \mathrm{~cm}$ in fork length (4-5 years old, mature) were sacrificed by decapitation and fixed in $10 \%$ buffered formalin. After fixation, the general arrangement of the accommodation system was observed macroscopically. The lens muscles were dehydrated in alcohol, and embedded in paraffin. Serial $10 \mu \mathrm{m}$ sections were made and stained according to the Bodian-Otsuka method. ${ }^{9}{ }^{9}$ The ciliary nerves which control the lens muscle were fixed in $2 \%$ glutaraldehyde in $0.1 \mathrm{M}$ cacodylate buffer (pH 7.4), post-fixed with $1 \%$ osmic acid in the same buffer and embedded in Epon. Thick transverse sections of the ciliary nerves were stained with toluidin blue for nerve fiber counting.
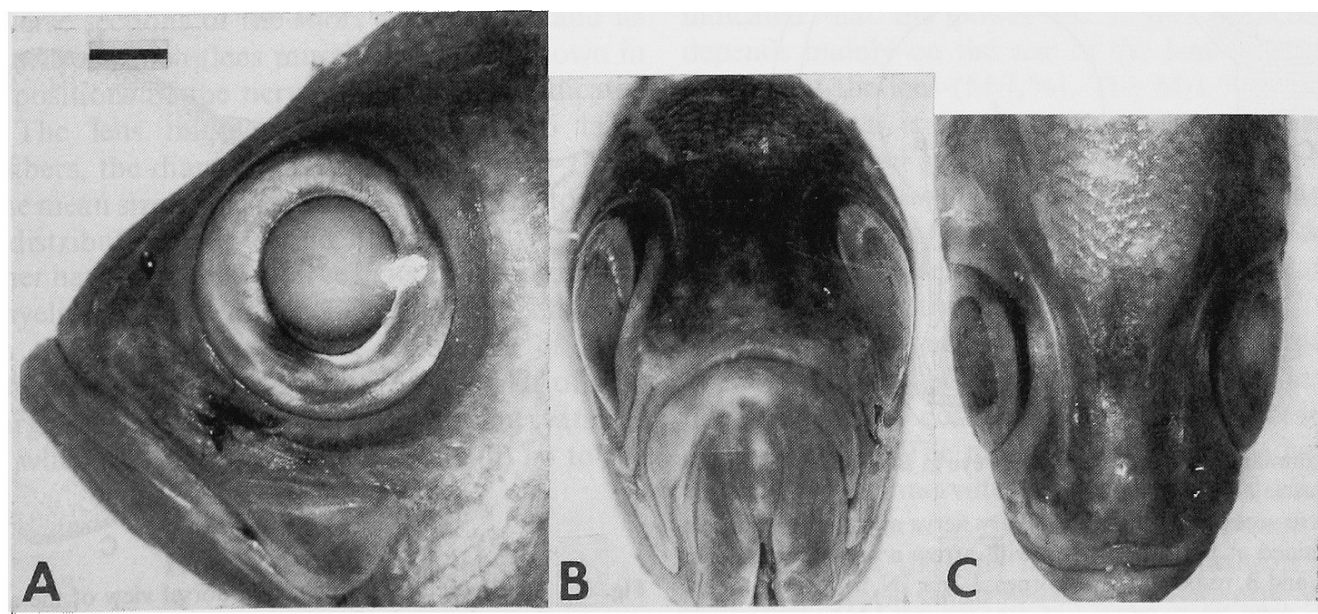

Fig. 1. Beryx splendens. Lateral (A), frontal (B), and dorsal view (C) of the head. Fork length is about $35 \mathrm{~cm}$. Scale bar, $1 \mathrm{~cm}$ 


\section{Results}

External Appearance of the Eye and Its Visual Axis

$B$. splendens has a relatively large eye (Fig. 1). Its pupillary aperture is oval (Fig. 1A). The external appearance of the head and eye position are shown in Figs. 1B and 1C. These photographs show that the eyes are directed up and forward. This indicates that the visual axis of the fish is also up and forward.

\section{Anatomy of the Accommodation System}

The accommodation system of the eye consist of three elements; a single lens muscle with pigmented covering, the lens and its suspensory and transparent ligaments, and the
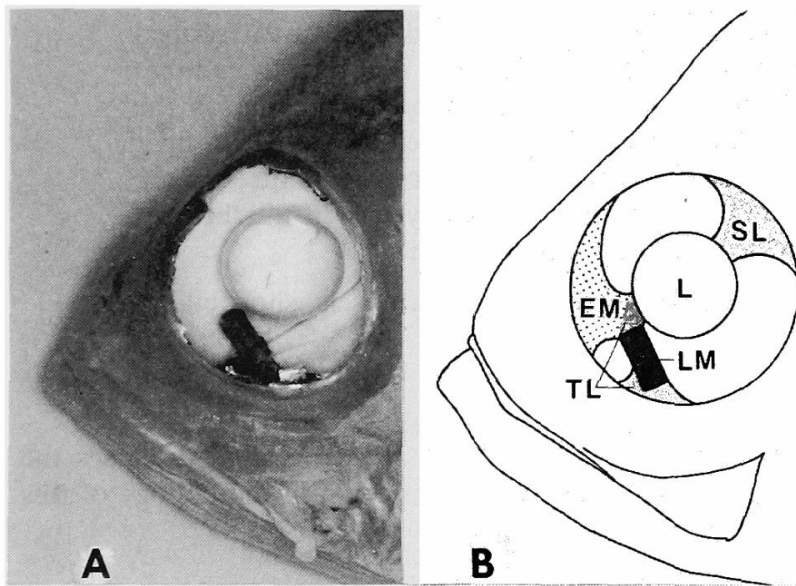

Fig. 2. B. splendens.

Lateral view of the head. Outerparts (cornea and iris) of the eye are removed to show the relative size of the lens and its associated lens muscle (A). (Lens diameter is about $17 \mathrm{~mm}$.) Schematic diagram of the eye (B). EM, thin elastic menbrane; L, lens; LM, lens muscle; SL, suspensory ligament; TL, thick transparent ligament.

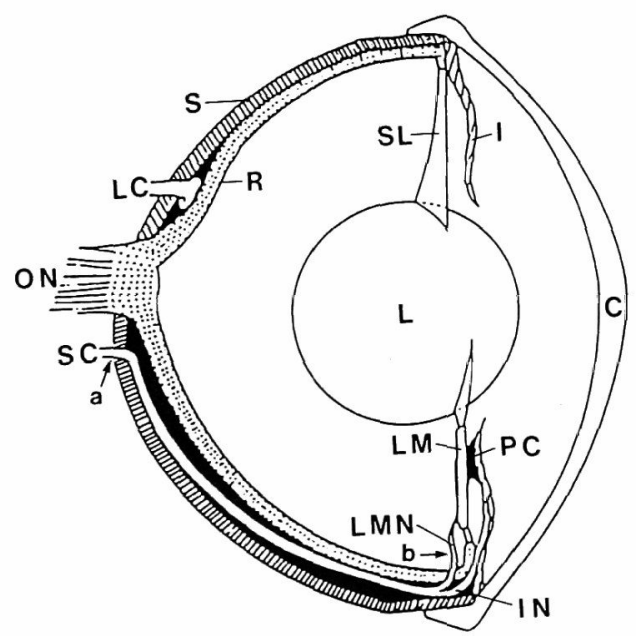

Fig. 3. Diagrammatic vertical section of the eye in B. splendens, showing the lens muscle and its nerve supply.

Transverse sections of the short ciliary nerve and the lens muscle nerve examined at points indicated with arrow $\mathrm{a}$ and $\mathrm{b}$, are shown in Figs. 6A and B, respectively. C, cornea; I, Iris; IN, iris nerve branch; L, lens; LC, long ciliary nerve; LM, lens muscle; LMN, lens muscle nerve; ON, optic nerve; PC, pigment covering; R, retina; S, sclera; $\mathrm{SC}$, short ciliary nerve; SL, suspensory ligament. short ciliary nerve which innervates the lens muscle. The efferent arrangements of the accommodation system are basically the same as those of bass ${ }^{6)}$ and are shown in Figs. 2 and 3.

\section{Lens Muscle and Its Associated Ligaments}

A single lens muscle is observed in the eyes (Figs. 2 and 3). The macroscopic appearance of the muscle is rectangular. The muscle is $11 \mathrm{~mm}$ long and $3.8 \mathrm{~mm}$ wide. The anterior (nasal) part of the muscle is attached to the lens by a thick transparent ligament which also extends as a thin elastic membrane toward the anterior margin of the iris (Fig. 2B). The posterior end of the muscle is tightly attached to the iris with a tick ligament (Fig. 2B).

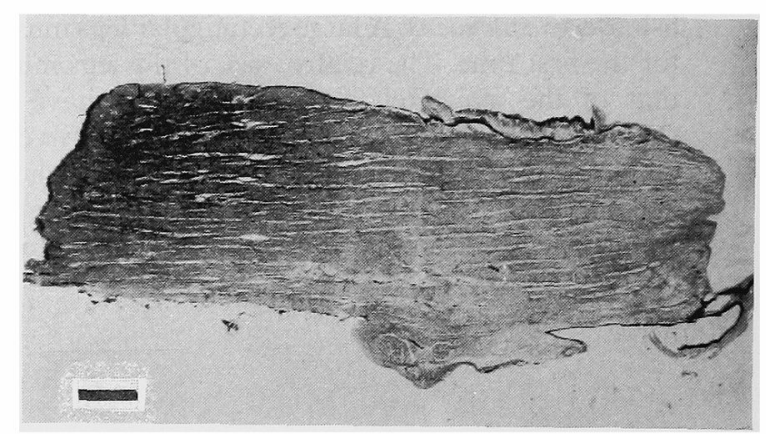

Fig. 4. Sagital section of the lens muscle of $B$. splendens. Scale bar, $1 \mathrm{~mm}$.

ciliary ganglion; lc, long ciliary nerve; on, optic nerve; sc, short ciliary nerve. $\mathrm{C}$, caudal direction; $\mathrm{N}$, nasal direction.

Table 1. Area size of lens and lens muscle calculated from photographs

\begin{tabular}{lcccc}
\hline Fish & $\begin{array}{c}\text { Body } \\
\text { length } \\
(\mathrm{cm})\end{array}$ & $\begin{array}{c}\text { Area of } \\
\text { lens (L) } \\
\left(\mathrm{mm}^{2}\right)\end{array}$ & $\begin{array}{c}\text { Area of lens } \\
\text { muscle (M) } \\
\left(\mathrm{mm}^{2}\right)\end{array}$ & $\begin{array}{r}\mathrm{M} / \mathrm{L} \\
(\%)\end{array}$ \\
\hline Beryx splendens & 35 & 226.8 & 34.0 & 15 \\
Scomber scomber* & 35 & 23.8 & 1.2 & 5 \\
Dicentrarchus labrax* & 40 & 38.5 & 7.4 & 19 \\
\hline
\end{tabular}

*: Cited from Somiya. ${ }^{\text {s }}$

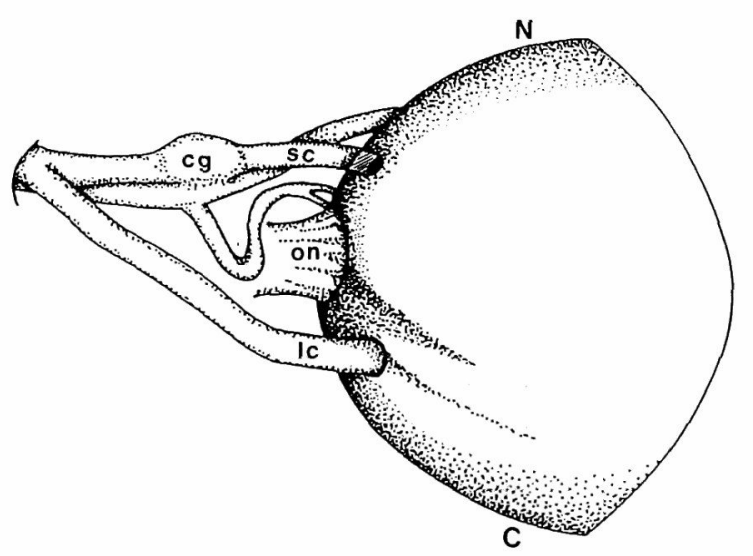

Fig. 5. Schematic arrangement of a dorsal view of the automatic nerve supply to the eye in $B$. splendens.

$\mathrm{cg}$, ciliary ganglion; lc, long ciliary nerve; on, optic nerve; sc, short ciliary nerve. $\mathrm{C}$, caudal direction; $\mathrm{N}$, nasal direction. 


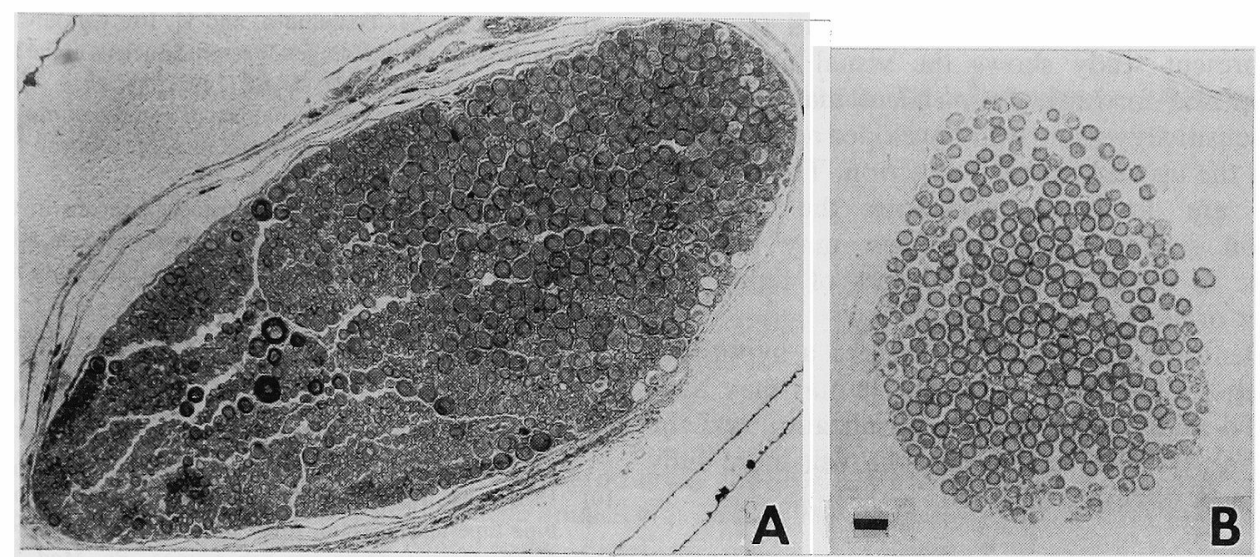

Fig. 6. Transverse sections of the whole short ciliary nerve (A) and the lens muscle nerve (B). Scale bar, $20 \mu \mathrm{m}$.

A melanin-pigmented covering is observed on the main central part of the muscle (Fig. 3). This covering acts as a restrainer to prevent the inward displacement of the muscle during contraction. The lens is suspended by a tough transparent ligament from the position of the dorso-caudal margin of the iris (Fig. 2B). These efferent arrangements of the accommodation system indicate that the direction of the lens moves from naso-dorsal to dorso-caudal and that the visual axis is directed up and forward.

Histologically, the lens muscle is composed of smooth muscle bundles which run parallel to the long-axis of the lens muscle (Fig. 4). The approximate size of the lens muscle was measured from photographs by the paper weight method $^{6)}$ and is shown in Table 1. To compare the size of the muscle with that of other fish species, the ratio of the area of the muscle to the lens was calculated. The area of the lens (L) and the lens muscle (M) were 226.8 and $34 \mathrm{~mm}^{2}$, respectively, and the area ratio of muscle/lens $(\mathrm{M} / \mathrm{L} \%)$ was about 15 .

\section{Nerve Fibers Controlling the Lens Muscle}

The schematic arrangement of a dorsal view of the autonomic nerve supply to the eye is shown in Fig. 5. This arrangement is similar to that of Scomber (mackerel). ${ }^{6}$ Thick transverse sections of the short ciliary nerve and its lens muscle nerve branch (lens muscle nerve) are shown in Fig. 6. The positions of the nerve examined are indicated in Fig. 3. The lens muscle nerve contains 296 large myelinated fibers, the diameter of which is about $7-13 \mu \mathrm{m}$ (Fig. 6B). The mean size of the fibers is $10.4 \mu \mathrm{m}$. A histogram of the fiber distribution is shown in Fig. 7.

On the other hand, the ciliary nerve in its entirety contains numerous myelinated fibres, particularly small fibers (Fig. $6 \mathrm{~A})$. Within the whole ciliary nerve, a bundle of large myelinated fibers can be observed in the right half of Fig. $6 \mathrm{~A}$. These large myelinated fibers (about 300 ) innervate the lens muscle, while the other fibers (mainly small) go to the iris.

\section{Discussion}

B. splendens possesses a pure rod and multibank retina (unpublished data) with a guanine type retinal tapetum

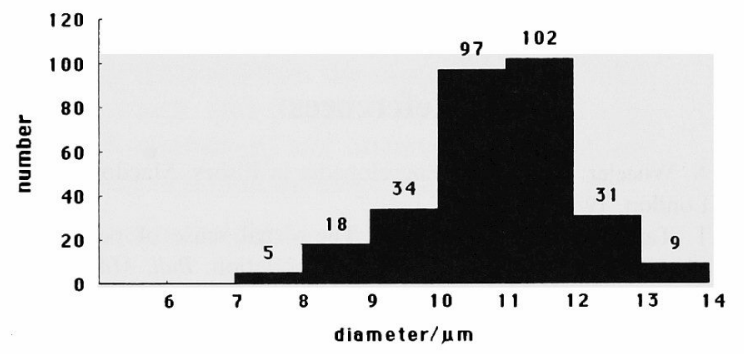

Fig. 7. Histogram of the fiber distribution of the lens muscle nerve in B. splendens.

Fiber counts are shown at the top of the column.

lucidum. ${ }^{10)}$ These retinal characteristics indicate that $B$. splendens has a typical deep-sea fish retina with high photosensitivity for a dim light deep-sea environment. ${ }^{11,12)}$ Indeed, reflection from the tapetum is at least $50 \%$ and quantal catch in the retina because of the tapetum is enhanced by a factor of about $1.5 .^{13-15)}$

The present study clearly demonstrates that the berycid deep-sea fish with pure rod and tapetum retina has a strikingly well-developed visual accommodation system, similar to shallow water fishes. In an earlier paper, Somiya ${ }^{6)}$ indicated that the power (or range) of accommodation depends mainly on the size of the lens muscle relative to the size of the lens $(\mathrm{M} / \mathrm{L} \%)$. The $\mathrm{M} / \mathrm{L} \%$ ratio of the eye in $B$. splendens is 15 . For comparison, the area ratios of $\mathrm{M} / \mathrm{L}$ in mackerel and bass are shown in Table 1 . This table shows that $B$. splendens has a lens muscle almost three times as large as that of mackerel in terms of the area ratio of M/L. Further more, B. splendens may have nearly the same wide accommodative range as the bass.

The lens muscle nerve contains about 300 large myelinated fibers and the mean size of the fibers is $10.4 \mu \mathrm{m}$. The large fibers reduce the conduction time but the cost in space is obviously high. The main advantage of the larger fibers is that they can innervate a greater number of muscle cells that small fibers. Actually, in the present histological preparation of the lens muscle, ramification of the large fiber into several small fibers was frequently observed.

$B$. splendens is a predatory species that feeds on other fish (myctophids, melanostromiatids, and chauliodontids), 
deep-sea shrimps, squid (Watasenia) and krill (Euphausia). ${ }^{16)}$ The present study shows the visual axis of $B$. splendens is up and forward. $B$. splendens may locate its prey using its sensitive eyes and well-developed accommodation system in the up and forward direction. The majority of its prey are luminous, therefore the powerful accommodation system of $B$. splendens may play an important role in detecting point sources of light from bioluminescent organisms or organs.

Recently, Denton and Locket ${ }^{17)}$ presented a hypothesis that some deep-sea fish with multibank retinas may have color vision. To examine the retinal specialization and the accommodation system of some deep-sea fish more fully will be the subject of future research.

Acknowledgments We thank Professor T. Abe, University of Tokyo, for his helpful advice, Professor B. V. Meyer-Rochow, University of the West Indies, for reviewing the manuscript and the officers and crew of the Enoshima-Maru for help in collecting fish. This study was supported by a grant from the Ito Foundation for the Advancement of Ichthyology in 1992.

\section{References}

1) A. Wheeler: The World Encyclopedia in Fishes, Macdonald \& Co, London, 1985, p. 134.

2) T. Tamura and W. J. Wisby: The visual sense of pelagic fishes especially the visual axis and accommodation. Bull. Mar. Sci. Gulf Carib., 13, 443-448 (1963).

3) K. Kimura and T. Tamura: On the direction of the movement in the visual accommodation of teleostean eyes. Nippon Suisan Gakkaishi, 32, 112-116 (1966).

4) H. Somiya and T. Tamura: Studies on the visual accommodation in fishes. Japan. J. Ichthyol., 20, 193-206 (1973).
5) H. Somiya, M. Yoshimoto, and H. Ito: Cytoarchitecture and fibre connection of the Edinger-Westphal nucleus in the flefish. Phil. Trans. R. Soc. Lond. B., 337, 73-81 (1992).

6) H. Somiya: Dynamic mechanism of visual accommodation in teleosts structure of the lens muscle and its nerve control. Proc. R. Soc. Lond B., 230, 77-91 (1987)

7) J. C. Wathey: Accomodation motor neurons in the foveate teleost Paralabrax clathratus: horseradish peroxidase labeling and axona morphometry, with comparisons to other cilialy nerve components. Brain Behav. Evol., 32, 1-16 (1988)

8) A. Rochon-Duvigneaud: Les Yeux et La Vision des Vertébrés, Masson et Cie, Paris, 1943, pp. 296-302.

9) N. Otsuka, A. Miyanaga, F. Tanaka, and A. Kimura: Neue Silberimpragnationsversuche zur Darstellung der Neurofibillen an Parafinschnitten. J. Kyoto Pref. Univ. Med., 68, 1125-1128 (1960).

10) H. Somiya: Fishes with eye shine; functional morphology of guanine type tapetum lucidum. Mar. Ecol. Prag. Ser., 2, 9-26 (1980).

11) N. A. Locket: Deep sea fish retinas. Br. Med. Bull., 26, 107-111 (1970).

12) N. A. Locket: Adaptations to the deep sea environment, in "Handbook of Sensory Physiology" (ed. by F. Cresciteli), Vol. VII/5, Springer-Verlag, Berlin, 1977, pp. 67-192.

13) E. J. Denton: Reflectors in fish. Sci. Am., 224, 65-72 (1971).

14) J. A. C. Nicol: Tapeta lucida of Vertebrates, in "Vertebrates Photoreceptor Optics" (ed. by J. M. Enoch and F. L. Tobey, Jr.), Springer-Berlag, Berlin, 1981, pp. 401-431.

15) H. Somiya and H. Niwa: Vision, in "Fish Physiology" (ed. by $Y$. Itazawa and I. Hanyu), Kouseisha-Kouseikaku, Tokyo, 1991, pp. 403-441 (in Japanese)

16) H. Masuzawa, Y. Kurata, and K. Onishi: Population Ecology of Japanese Alfonsin and other Demersal Fishes, Suisan Kenkyu Soushyo No. 28, Suisan Shigen Hogo Kyoukai, 1975, pp. 25-71 (in Japanese).

17) E. J. Denton and N. A. Locket: Possible wavelength discrimination by multibank retinae in deep-sea fishes. J. Mar. Biol. Ass. U. K., 69 , 409-435 (1989). 